\title{
Vorwort zur ersten Auflage
}

D ie folgenden Darlegungen wissen sich in vollem Gegensatz zu den geistigen Strömungen, die heute āuBerlich noch vorherrschen.

Sie müssen abgelehnt werden von dem konventionellen und offiziellen Idealismus. Denn sie behandeln viel zu sehr die Probleme als im FluB und verlangen viel zu eingreifende Umwandlungen, als daß sie demjenigen gefallen könnten, dem alles fest und fertig dūnkt.

Sie müssen ferner abgelehnt werden von dem Naturalismus jeder Färbung. Denn viel zu energisch verfechten sie eine geistige Wirklichkeit jenseits des sinnlichen Daseins, und viel zu entschieden verwerfen sie alle Kompromisse zwischen den in Wahrheit unversöhnlichen Gegensätzen, als daB sie nicht die volle Gegnerschaft jener Richtung auf sich nehmen müBten.

Endlich müssen sie auch abgelehnt werden von der selbstbewußten und selbstgerechten Fachgelehrsamkeit. Wo alles Streben nach Weltanschauung und zusammenhaltender Überzeugung eine leere Utopie dünkt, wo man die Philosophie nur soweit gelten läßt als sie auf alle Prinzipienfragen verzichtet und entweder Geschichte oder Naturwissenschaft wird, da kann 
sich kein Verstāndnis finden für ein Streben nach einer inneren Wendung aus dem Großen und Ganzen.

So sind wir auf die Minorität angewiesen und müssen uns besonders in unserer eignen Wissenschaft recht vereinsamt fühlen. Aber das schreckt uns nicht im mindesten. Einmal ist diese Minoritāt nicht so klein wie sie sich bei der Zerstreuung der Geister ausnimmt, und dann gibt es keine bessere Position als die in einer Minorität, welche ein unabweisbares Bedürfnis und auch schon den inneren Zug der Zeit für sich hat. $\mathrm{DaB}$ dem heutigen Kulturleben eine alles durchdringende und zusammenhaltende Hauptüberzeugung, ein gemeinsames Ideal fehlt, das kommt immer deutlicher zur Empfindung, zugleich aber auch dieses, daB wir damit einer geistigen Substanz entbehren, ja überhaupt einen Lebensinhalt, der diesen Namen verdient, einzubüBen drohen. So haben wir um ein geistiges Leben überhaupt wie um etwas neues zu kämpfen. Ist aber ein solches Problem einmal wach geworden, so kann es nicht wieder einschlummern, so läBt es sich auch nicht als eine Nebensache behandeln. Vielmehr wird es die Gemüter immer mächtiger bewegen und immer mehr den Vordergrund des Lebens einnehmen. Die Zeit dürstet nach einem fester begründeten und zugleich größeren und freieren Leben, nach mehr Verwandlung der Wirklichkeit in innere Erfahrung der Menschheit; sie bedarf dafür einer gröBeren Aktivität des Geistes, sie bedarf einer kräftigen Urerzeugung und Neubewährung geistigen Lebens. Und einem solchen Problem sollte die Philosophie ihre Mitarbeit versagen, es als ein minder "exaktes" von sich schieben!

Will sie aber daran mitarbeiten, so muß sie neben den Spezialuntersuchungen, deren Wert in vollen Ehren bleibt, wieder eine Wendung ins Prinzipielle und Ganze vollziehen; so darf sie den Gegensatz des Idealismus und Naturalismus die unliebsamen Schlagwörter seien hier der Kürze halber entschuldigt - nicht verschleiern und durch einen matten Synkretismus abschwächen, sondern sie hat sich entschieden für den Idealismus zu erklären, freilich zugleich auch eine neue, wesenhaftere Art des Idealismus zu fordern; so kann sie sich 
endlich bei der Entfaltung der Geisteswelt nicht mit einer bloßen Schilderung und Zurechtlegung empirischer Art begnügen, sondern sie muß einen überlegenen Standort gegenüber der zerstreuten und fließenden Erfahrung erringen, von hier aus eine Umwandlung der Welt des ersten Eindruckes unternehmen und auch dem Leben neue Kräfte zuführen. Gegenüber der unerträglichen Verworrenheit der gegenwärtigen Lage muB sie auf einer schärferen Scheidung der Geister bestehen; die notwendige Vertiefung des Lebens kann sie nur erreichen durch einen Bruch mit dem nächsten Dasein, durch eine Umkehrung der vorgefundenen Lage. Ohne Wagnis läßt sich dabei nicht auskommen, numquam periclum sine periclo vincitur.

In den Dienst dieser Aufgaben stellen sich die folgenden Ausführungen. Ihrer Unvollkommenheit ist sich der Verfasser vollauf bewußt; gern hätte er besseres geboten als hier geboten ist. Aber die Gesinnungsgenossen darf er bitten, der Schwierigkeiten eingedenk zu sein, mit denen ein solches Unternehmen in dem geistigen Dunkel der Gegenwart zu kämpfen hat, und von Herzen würde er sich freuen, wenn die leitenden Ideen, über deren schlieBlichen Sieg kein Zweifel sein kann, von Anderen glücklicher und eindringlicher verfochten würden.

Jena, im Herbst 1895. 